Original Research Article

\title{
A cross sectional study of knowledge, attitude and practices related to fixed dose combinations use among clinicians and resident doctors at a tertiary care teaching hospital in India
}

\author{
Mahesh N. Belhekar, Tejal C. Patel*, Prasad R. Pandit, Kiran A. Bhave
}

\begin{abstract}
Department of Pharmacology, HBT Medical College and Dr. RN Cooper Municipal General Hospital, Juhu, Mumbai 56, Maharashtra, India
\end{abstract}

Received: 24 July 2017 Accepted: 22 August 2017

\section{*Correspondence to: \\ Dr. Tejal C. Patel, \\ Email: drtejalchetan@ gmail.com}

Copyright: (C) the author(s), publisher and licensee Medip Academy. This is an openaccess article distributed under the terms of the Creative Commons Attribution NonCommercial License, which permits unrestricted noncommercial use, distribution, and reproduction in any medium, provided the original work is properly cited.

\begin{abstract}
Background: In the year 2016, Government of India had banned 350 fixed dose combinations (FDCs) for the safety and efficacy purpose. The present study was conducted to assess the knowledge, attitude and practices of the clinicians and residents about the use of FDCs at a tertiary care hospital.

Methods: A questionnaire based study was conducted at a tertiary care hospital after getting approval from institutional ethics committee. A pre-validated questionnaire comprising of 30 items was distributed to 100 participants. The questionnaire focused on the prescribing behaviour, knowledge on therapeutic efficacy, advantages and limitations of FDC use, clinician perception regarding FDC use and the strategies to improve the awareness about the regulatory updates of the marketed drugs.

Results: Total 52/100 clinicians responded. Out of these, $88 \%$ prescribed FDCs in their practice, $62 \%$ prescribed FDCs only after ensuring therapeutic efficacy and $50 \%$ prescribed WHO approved FDCs. $64 \%$ were aware of the recent ban on some FDCs by DCGI. Internet was the most common source of latest updates on the regulatory status of the drug, as stated by $55 \%$ clinicians. All clinicians agreed that efforts are needed to ensure that prescribers remain up to date about the postmarketing regulatory status of the drugs.

Conclusions: Even though many clinicians prescribe FDCs regularly, they appreciated the step of banning some FDCs; however, the clinicians need to be trained to update themselves regularly. The source and relevance of these updates should be taught to the undergraduate students during their training period which can be reemphasized during post graduate training period.
\end{abstract}

Keywords: Irrational fixed dose combinations, Prescription, Rational prescribing

\section{INTRODUCTION}

Fixed dose combinations (FDCs) are combination products of two or more active pharmaceutical ingredients (APIs) in a single dosage form. ${ }^{1}$ The Food and Drug Administration, USA defines a combination product as 'a product composed of any combination of a drug and a device or a biological product and a device or a drug and a biological product or a drug, device, and a biological product'. ${ }^{2}$ FDCs are available for the treatment of various disorders e.g. cardiovascular diseases, diabetes, infectious diseases (bacterial infections), gastrointestinal infections, orthopaedic conditions, cough and cold, HIV infection, tuberculosis, psychiatric disorders and respiratory diseases. $^{3}$

Use of FDCs is associated with many advantages like exerting synergistic action, increased efficacy (e.g. cotrimoxazole), reduced adverse effects (e.g. levodopa with carbidopa, thiazides with potassium sparing diuretics), reduced pill burden and cost of therapy and hence better patient compliance (e.g. anti-tubercular drug combinations). ${ }^{4}$ FDCs are highly popular in the Indian pharmaceutical market and have been particularly 
flourishing in the last few years. The rationality of FDCs is based on certain aspects such as, the drugs in the combination should act by different mechanisms, have similar pharmacokinetics profile, and the combination should be devoid of supra-additive toxicity. ${ }^{5}$

The FDCs do have some demerits, such as, dosage alteration of one drug is not possible without altering the dose of the other drug, differing pharmacokinetics of constituent drugs pose the problem in the frequency of administration of the formulation and in some FDCs, there are increased chances of occurrence of adverse drug effects and drug interactions when compared with both drugs given individually.

The $17^{\text {th }}$ World Health Organization (WHO) Model List of essential medicines (March 2011) contains only 25 approved FDCs whereas the National list of essential drugs of India has 354 essential drugs including 14 FDCs. ${ }^{6,7}$ The WHO Model list of Essential Drugs provides examples of some rational FDCs such as; sulfamethoxazole + trimethoprim, antitubercular FDCs like rifampicin + isoniazid, isoniazid + ethambutol, and antiparkinsonism FDCs like levodopa + carbidopa. ${ }^{8}$

Most of the popular and highly profitable FDCs, marketed widely in the Indian drug market include analgesics, tonics, antimicrobials, cough and cold preparations, multivitamins, iron preparations and antacids. The Indian laws are not properly defined to grant marketing approval by central or state drug controlling authorities, hence there is an increase in the number of irrational FDCs in the Indian drug market at an alarming rate. The concept of rational FDCs has not yet penetrated in the minds of physicians; hence evaluation is needed, as large numbers of FDCs are of little importance in terms of effective health care. ${ }^{9}$ Also, the safety profile of the established drugs may change when they are combined in a single formulation. There is a growing concern about the increasing number of irrational FDCs in the developing countries which impose unnecessary financial burden, the occurrence of adverse drug reactions, including allergy, hospitalization and ultimately reducing the quality of life. The most pressing concern with irrational FDCs is that they expose patients to unnecessary risk of adverse drug reactions. ${ }^{10,11}$

Over the years the Indian drug regulatory authority, Drugs Controller General of India (DCGI) had issued ban notifications on certain FDCs where there was no therapeutic advantage of the combination over individual drug. ${ }^{12,13}$ Upon realizing the threat of rampant prescribing of FDCs, the Central Drugs Standard Control Organization (CDSCO) decided to put ban on certain FDCS for which there was no therapeutic justification available, those combinations that were likely to cause risk to human health and for which there are safer alternatives available in the market. ${ }^{14}$

A study of knowledge, attitude and practice is the most important tool to assess the benefits and lacunae about a given research subject in the community, so that effective measures can be implemented in that direction to bring about the change. A large number of FDCs are manufactured every year and hence the knowledge about prescribing FDCs is becoming increasingly important for better health outcomes. ${ }^{15}$ Tertiary care teaching hospitals have a dual role to play in terms of educating medical students and simultaneously providing health care facilities to the patients. Since clinicians and resident doctors are directly involved in patient management, their awareness about prescribing medicines is of paramount importance. Hence, the present study was conducted to assess the knowledge, attitude and practices of FDCs among clinicians and resident doctors at a tertiary care hospital in India so as to propose strategies for restricting the prescription of FDCs.

\section{METHODS}

This was a cross-sectional observational questionnaire based study. Informed consent was administered prior to enrollment. Study duration was from 01 August 2016 to 31 October 2016. Study site was Department of Pharmacology, HBT Medical College and Dr RN Cooper Municipal General Hospital, Juhu, Mumbai. After thorough literature search, a questionnaire was designed. The questions were prepared with an objective of seeking information from the clinicians and residents related to the knowledge, attitude and practices pertaining to various aspects of FDCs. The questionnaire comprised of 30 items, out of which 10 questions were pertaining to knowledge on FDCs, 11 questions were pertaining to attitude of clinicians and residents towards prescribing FDCs and 9 questions focused on prescription practices related to FDCs. Content validity of the questionnaire was done from the subject experts (faculty of Department of Pharmacology). Those who were not willing to participate or did not return the questionnaire or returning incompletely filled forms were excluded from the study.

\section{Statistical analysis}

No formal statistical test was applied. The results were to be descriptive in nature, hence, the collected data was expressed in percentages. The percentage was calculated by using Microsoft Excel 2010.

\section{RESULTS}

Out of 100 questionnaires distributed, 52 participants from various specialties, such as internal medicine, pediatrics, general surgery, obstetrics and gynaecology, psychiatry, dermatology and orthopedics responded at the end of 3 months. Majority of the respondents (65\%) answered correctly by stating that they do ensure therapeutic usefulness of FDCs before prescribing. Total $65 \%$ replied that they regularly update their knowledge on drug status from time to time. When asked that in FDCs the individual dose of the drug could be sub-therapeutic, only $23 \%$ of responded that they were not aware whether the doses of 
individual components in FDC were sub-therapeutic or no. It was interesting to note that $69 \%$ of the respondents were aware of the recent ban of DCGI on certain FDCs. (Figure $1)$.

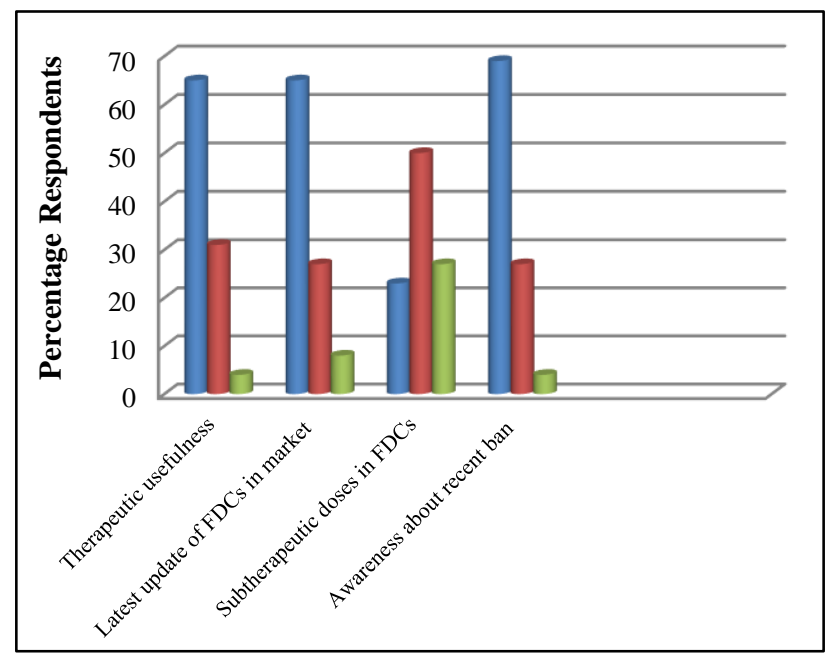

Figure 1: Knowledge of the respondents' towards prescribing practices with regards to FDCs.

When asked about the source of information on the latest updates of the drug status after marketing, almost $60 \%$ replied that they get this info from the internet, but $38 \%$ relied on pharmaceutical industry sources for latest postmarketing drug updates (Figure 2).

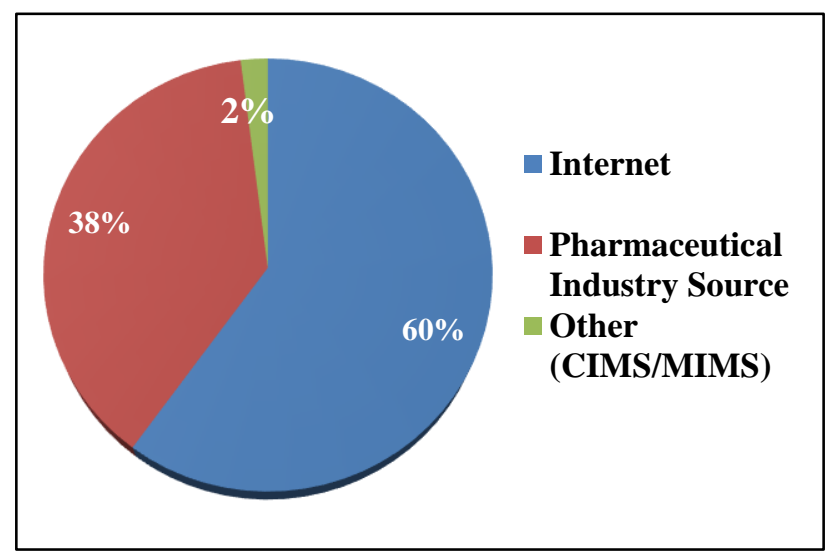

Figure 2: Source of Information on the updates related to status of FDCs in the market.

Majority of the respondents were not sure about the occurrence of ADRs with the FDC use and $23 \%$ stated that ADR does not occur with FDCs use. None of them stated that occurrence of ADR increases with FDC use (Figure $3)$.

When asked questions on prescribing practices almost $88 \%$ stated they use FDCs in practice, and $62 \%$ said that they do consider therapeutic effectiveness of this FDCs before prescribing. Total $50 \%$ of them stated they prescribe FDCs only after confirming their approvals by
WHO. It was interesting to note that prescriptions of FDCs were not influenced by the pressure from the medical representatives or any advertising campaign/promotional literature of the pharmaceutical company in $81 \%$ of respondents. Also, 58\% of respondents said that they prefer to prescribe FDCs over single drug but when asked about preference of FDCs in the presence of co-morbid conditions, majority (62\%) of them stated they do not prefer FDCs in such cases (Figure 4).

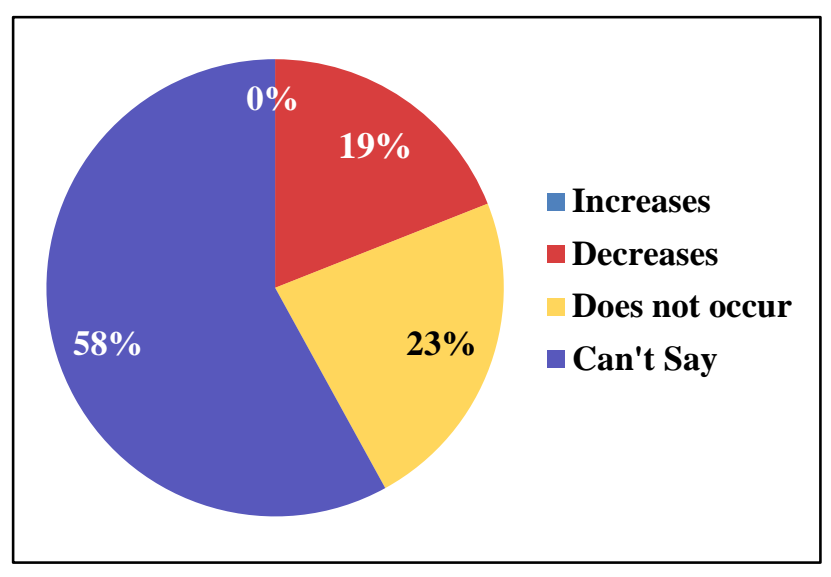

Figure 3: Knowledge of the respondents regarding the incidence of ADRs due to FDC use.

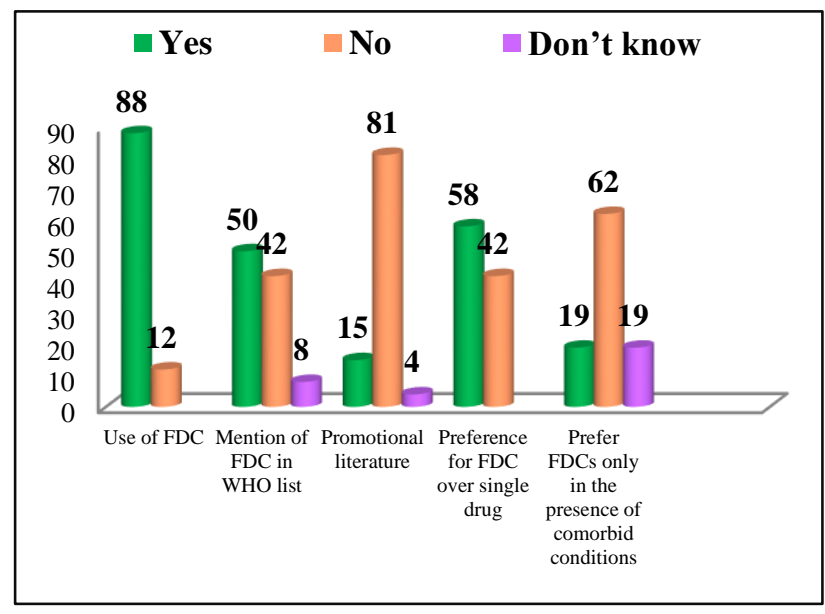

Figure 4: Assessment of prescribing practices of the respondents with regards to FDCs use.

It was found that, $88 \%$ of clinicians agreed that the recent ban on certain FDCs by DCGI is completely justified. Majority of them $(81 \%)$ disagreed to the statement that FDCs are always therapeutically more effective. That the health regulatory authorities should restrict the use of FDCs only in certain diseases was felt by $65 \%$ of the respondents. Most of them $(88 \%)$ too felt that the updates on the status of the drug after its marketing is crucial and all the respondents agreed that there is a need to have a system which will increase the awareness of the prescribers regarding the updates on the status of the drug after marketing or the prescribers get alerts on the status of FDCs after marketing. 
Table 1: Assessment of attitude of the respondents $(n=52)$ in percentage towards FDCs use.

\begin{tabular}{|llllll|}
\hline Question & $\begin{array}{l}\text { Strongly } \\
\text { disagree }\end{array}$ & Disagree & Neutral & Agree & $\begin{array}{l}\text { Strongly } \\
\text { agree }\end{array}$ \\
\hline Decision on FDC ban is justified & 0 & 4 & 8 & 77 & 11 \\
\hline FDCs are always therapeutically more Effective & 4 & 77 & 11 & 8 & 0 \\
\hline FDCs reduce medication errors & 4 & 35 & 23 & 38 & 0 \\
\hline $\begin{array}{l}\text { FDCs use increases health risk and economic burden on } \\
\text { patients }\end{array}$ & 4 & 15 & 19 & 50 & 12 \\
\hline FDCs pose restrictions on personalising drug treatment & 0 & 27 & 19 & 50 & 4 \\
\hline $\begin{array}{l}\text { Pressure from medical representatives influence prescription of } \\
\text { FDCs }\end{array}$ & 8 & 38 & 15 & 35 & 4 \\
\hline $\begin{array}{l}\text { Regulatory authority restrict use of FDCs only in certain } \\
\text { diseases }\end{array}$ & 0 & 23 & 12 & 61 & 4 \\
\hline $\begin{array}{l}\text { Information on the updates of drug after its marketing are } \\
\text { crucial }\end{array}$ & 0 & 0 & 12 & 80 & 8 \\
\hline $\begin{array}{l}\text { Need for spreading the awareness among the prescribers to get } \\
\text { the status of FDCs after marketing }\end{array}$ & 0 & 0 & 0 & 77 & 23 \\
\hline $\begin{array}{l}\text { Display of posters and charts in outpatient departments to } \\
\text { spread the awareness }\end{array}$ & 0 & 6 & 4 & 73 & 17 \\
\hline $\begin{array}{l}\text { Inclusion of importance of updates on drug status to be } \\
\text { incorporated in undergraduate teaching curriculum }\end{array}$ & 0 & 0 & 2 & 79 & 19 \\
\hline
\end{tabular}

Table 2: Most common FDCs prescribed by the respondents pertaining to their specialty.

\begin{tabular}{|c|c|c|}
\hline Class of FDC & Name of FDC & $\begin{array}{l}\text { No. of } \\
\text { respondents }\end{array}$ \\
\hline \multirow{5}{*}{ Antimicrobials } & Amoxiclav & 10 \\
\hline & Cotrimoxazole & 8 \\
\hline & $\begin{array}{l}\text { Azithromycin }+ \\
\text { Cefixime }\end{array}$ & 4 \\
\hline & $\begin{array}{l}\text { Ofloxacin }+ \\
\text { Ornidazole }\end{array}$ & 4 \\
\hline & HRZE & 2 \\
\hline \multirow{4}{*}{$\begin{array}{l}\text { Anti-psychotic } \\
\text { drugs }\end{array}$} & $\begin{array}{l}\text { Paroxetine + } \\
\text { Clonazepam }\end{array}$ & 2 \\
\hline & $\begin{array}{l}\text { Escitalopram + } \\
\text { Clonazepam }\end{array}$ & 4 \\
\hline & $\begin{array}{l}\text { Trifluperazine }+ \\
\text { Trihexyphenidyl }\end{array}$ & 2 \\
\hline & $\begin{array}{l}\text { Resperidone + } \\
\text { Trihexyphenidyl }\end{array}$ & 2 \\
\hline GIT drugs & $\begin{array}{l}\text { Esomeprazole } \\
\text { +Domperidone }\end{array}$ & 4 \\
\hline \multirow{2}{*}{ Analgesics } & $\begin{array}{l}\text { Aceclofenac }+ \\
\text { Serratiopeptidase }\end{array}$ & 4 \\
\hline & $\begin{array}{l}\text { Paracetamol + } \\
\text { Chlorpheniramine }\end{array}$ & 2 \\
\hline \multirow{2}{*}{$\begin{array}{l}\text { Anti- } \\
\text { hypertensive } \\
\text { drugs }\end{array}$} & $\begin{array}{l}\text { Amlodipine }+ \\
\text { Atenolol }\end{array}$ & 4 \\
\hline & $\begin{array}{l}\text { Telmisartan }+ \\
\text { Chlorthalidone }\end{array}$ & 2 \\
\hline $\begin{array}{l}\text { Anti-diabetic } \\
\text { drugs }\end{array}$ & $\begin{array}{l}\text { Names not } \\
\text { specified }\end{array}$ & 2 \\
\hline
\end{tabular}

To some extent, this can be achieved by displaying posters and charts in the OPDs and in the wards as suggested by $90 \%$ respondents. Also, $98 \%$ respondents agreed that the knowledge of regulatory status of the drug after its marketing is important for every treating doctor and that aspect also needs to be taught to the undergraduate students and can be reiterated in the post-graduate training period (Table 1).

When we asked them to give names of 2 or more FDCs recently banned, out of 12 examples of FDCs, only 6 FDCs actually matched with the recent FDCs banned by the DCGI.

The most common FDCs prescribed by the respondents are summarized in Table 2.

When asked about reasons for your preference/ non preference for FDCs. Some of the reasons for preference for FDCs were; improved compliance, better patient acceptability and tolerability and synergistic actions of some drugs. Some of the reasons for non-preference were stated as adverse drug reactions due to FDCs cannot be attributed to any single component and difficulty in titrating dose later with the FDCs use.

\section{DISCUSSION}

To curb the problem of rampant prescribing of FDCs, the Government of India had prohibited the manufacturing and sale of 350 irrational FDCs on 10th March 2016. This study was therefore planned to assess the knowledge, attitude and practices of clinicians on various aspects 
pertaining to FDCs use and also their perspective while prescribing FDCs in clinical practice.

On assessing the knowledge aspect of the respondents pertaining to FDC use, we found that $88 \%$ of them use FDCs in practice, $62 \%$ stated that they do consider therapeutic effectiveness of FDCs before prescribing. This finding were similar to the findings presented in a study conducted by George et al on assessment of awareness about use of FDCs among the dental practitioners where they mentioned $96 \%$ of dental practitioners prescribe FDCs. ${ }^{16}$ In the same study by George et al, $56 \%$ of the respondents had mentioned that FDCs have fewer side effects. In contrast to this finding, 58\% the respondents in our study mentioned that the incidence of adverse drug reactions in fact increases with the use of FDCs.

Regarding knowledge about the banned FDCs, a study reported by Goswami et al, on resident doctors stated that more than half $(58 \%)$ of the resident doctors were not able to mention a single FDC banned in India. ${ }^{15}$ Similar finding was reported by Rasayam et al, where they found that $9 \%$ of the practitioners actually prescribed the banned FDCs. ${ }^{9}$ These findings reflect that there is considerable lack of knowledge among the prescribers regarding the ban by DCGI on certain FDCs, which is possibly the key factor responsible for the misuse of FDCs and perhaps that is responsible for increase in the cost of treatment and occurrence of adverse effects following the use of FDCs. In contrast to these findings, it was interesting to observe that $2 / 3^{\text {rd }}$ of the respondents of our study were aware of the recent ban of DCGI on certain FDCs and in fact $88 \%$ of the respondents in our study stated that the ban was justified.

When asked about the common source of information on FDCs, a study by Goswami et al found that $71 \%$ of clinicians mentioned medical representatives and only $19 \%$ of them used internet whereas a study conducted by Rasayam et al, stated that $95 \%$ of the practitioners gathered the information from the drug retailers. ${ }^{9,15}$ Only $5 \%$ of these prescribers accessed books, journals and web sites for getting information of the FDCs.

Another study conducted by Sharma et al, mentioned that $32 \%$ of clinicians and resident doctors use monthly index of medical specialities (MIMS) as a source of information on FDCs and only $20 \%$ of them use websites. ${ }^{17}$ In contrast to these finding, $60 \%$ respondents in our study used the internet as a main source of information next to the information from medical representatives.

These findings suggest that the busy schedule of the clinicians makes it difficult to access the authentic resources like text-books, printed material (MIMS) available on getting information on the regulatory status of the drug in the market. Perhaps, displaying charts or posters in the OPDs or wards may help in spreading the information on the regulatory status of the marketed drugs as suggested by many respondents of our study.
In our study, FDC of amoxicillin and clavulanic acid and cotrimoxazole were the most common antimicrobial FDCs prescribed, which was similar to the findings reported by the previous studies, Goswami et al, and Rayasam et al. ${ }^{9}$ As suggested by Rasayam et al, that FDCs are cost effective only when they are used for certain chronic diseases such as tuberculosis, HIV infections and leprosy, $65 \%$ of the respondents in our study also agreed to the restriction by the regulatory authorities on the use of FDCs only in certain diseases. In any irrational FDC, there is a possibility of an adverse event because of administration of an unnecessary component, or where the dose titration is obligatory as expressed by Gupta et al. ${ }^{18}$ Hence, the clinicians should always consider the rationality of FDCs before prescribing.

Although $88 \%$ of our respondents were aware of and felt that the recent DCGI ban on several FDCs was justified, many respondents failed to list the recently banned FDCs by DCGI, which reflects that the awareness was incomplete, possibly due to the lack of robust communication methods between the regulatory authorities and the practising clinicians. Only update of information of the website may not be sufficient. Further, for healthcare professionals it is extremely imperative to keep themselves updated on the regulatory status of the drug from time to time. Sensitization on the rational use of drugs, sources of drug updates, and importance of awareness on the drug updates therefore should be taught to the medical students' right from their early training period. Therefore, academicians too should take efforts to teach the importance of rational prescribing to undergraduate students and the same can be reinforced during post graduate training period. These steps may help to minimize the rampant irrational prescribing by the clinicians to some extent.

In order to reduce the rampant use of irrational FDCs in the country a multistep approach is required. The regulatory authorities along with pharmaceutical companies, treating clinicians and academicians need to develop a strategy that should restrict the entry of irrational FDCs in the market.

\section{Limitations}

Only limitation of this study was less response rate. This may be due to busy working schedule of clinicians and resident doctors.

\section{CONCLUSION}

The clinicians and the residents had satisfactory knowledge on the FDCs and many of them were aware of the recent ban by DCGI. However, many of them were unaware of the FDCs which were banned by DCGI. Though, the ban by DCGI was acceptable and justified by the clinicians, majority of them felt that the decisions on the regulatory status of the drugs after marketing or alerts related to drugs status should be made available to 
prescribers at regular intervals. Awareness can be spread by displaying posters and charts in the OPDs as well as in the wards. Such information is crucial, and should be incorporated in the undergraduate curriculum and can be reemphasized in their post graduate training period.

\section{ACKNOWLEDGEMENTS}

The authors would like to acknowledge Dr. Sweta Tondare, Dr. Vijay Kokani for data collection. Also, all the respondents who had participated in this study.

Funding: No funding sources

Conflict of interest: None declared

Ethical approval: The study was approved by the Institutional Ethics Committee (HO/10729/RNCH)

\section{REFERENCES}

1. WHO drug information: World Health Organization (Geneva). 2003;17(3):85. Available at: http://apps.who.int/medicinedocs/en/d/Js4955e

2. Sreedhar D, Subramanian G, Udupa N. Combination drugs: are they rational? Curr Sci. 2006;91:406.

3. Panda J, Tiwari P, Uppal R. Evaluation of rationality of some FDC: Focus on antihypertensive drugs. Indian J Pharm Sci. 2006;68:649-52.

4. Balat JD, Gandhi AM, Patel PP, Dikshit RK. A study of use of fixed dose combinations in Ahmedabad, India. Indian J Pharmacol. 2014;46:503-9.

5. Amitava $S$, Indian market's fixation with fixed dose combinations (Editorial) Rational Drug Bulletin. 2002;12:1.

6. World Health Organization (WHO) Model List of Essential Medicines. 17 $7^{\text {th }}$ list (updated), March 2011. Available at: http://www.who.int/medicines/publications/essential medicines/en/index.html [Last accessed on 10th April 2016]

7. National list of essential medicines; 2003. Available at: http://www.serowho.int/linkfiles/essential drugs and medicines india.pdf [Last accessed on 10th April 2016].

8. World Health Organization. The Use of Essential Drugs. WHO Technical Report Series 850. Geneva: World Health Organization; 1995.

9. Rayasam SP, Dudhgaonkar SS, Dakhale GN, Hire RC, Deshmukh PS, Gaikwad NN. The irrational fixed dose combinations in the Indian drug market: an evaluation of prescribing pattern using WHO guidelines. Int $\mathbf{J}$ Basic Clin Pharmacol. 2013;2:452-7.

10. Baiardini I, Guerra L, Pasquali M, Bonadonna P, Pasalaqua G, Canonica GW. Quality of Life in Patients with Adverse Reactions to Drugs: Preliminary Results from a New Questionnaire. J Allergy ClinImmunol. 2004;113(2):s70.

11. Gautam CS, Aditya S. Irrational drug combination: need to sensitize undergraduates. Ind J Pharmacol. 2006;38:167-70.

12. Tripathi KD (ed). Appendix 2. Drugs and fixed dose combinations banned in India. In: Essentials of medical pharmacology, $5^{\text {th }}$ Edn. New Delhi: Jaypee Brothers; 2004:847-848.

13. Drugs banned in India. Available at: http://www.cdsco.nic.in/drugs\%20banned\%20in\% 20th ed. 20country.pdf [Last accessed on 20th April 2016]

14. Prohibition of Fixed Dose Combination Drugs for Human Use Under Section 26A of Drugs and Cosmetics Act, 1940; 2016. Available at: http://www.cdsco.nic.in/writereaddata/SKM_12 03 2016.pdf)

15. Goswami N, Gandhi A, Patel P, Dikshit R. An evaluation of knowledge, attitude and practices about prescribing fixed dose combinations among resident doctors. Perspect Clin Res. 2013;4:130-5.

16. George B. Evaluation of awareness about Fixed Dose Combination among the practitioners in Dentistry: A Question based study. Int. J. Chem. And Life Sci. 2014;3(05):1322-24.

17. Sharma K, Sharma A, Singh V, Pilania D, Sharma Y. Irrational Fixed Dose Combinations \& Need for Intervention: Understanding of Dental Clinicians and Residents. Journal of Clinical and Diagnostic Research. 2014;8(12):ZC49-52.

18. Gupta YK, Ramachandran SS. Fixed dose drug combinations: Issues and challenges in India. Indian J Pharmacol. 2016;48:347-9.

Cite this article as: Belhekar MN, Patel TC, Pandit PR, Bhave KA. A cross sectional study of knowledge, attitude and practices related to fixed dose combinations use among clinicians and resident doctors at a tertiary care teaching hospital in India. Int J Basic Clin Pharmacol 2017;6:2395-400. 